\title{
AS "DISQUISITIONES" DO NATURALISTA ARRUDA DA CÂMARA (1752-1811) E AS RELAÇÕES ENTRE A QUÍMICA E A FISIOLOGIA NO FINAL DO SÉCULO DAS LUZES
}

\author{
Argus Vasconcelos de Almeida \\ Departamento de Biologia - Universidade Federal Rural de Pernambuco, Av. D. Manoel de Medeiros, s/n, Dois Irmãos - \\ 52171-030 - Recife - PE \\ Francisco de Oliveira Magalhães \\ Departamento de Química - Universidade Federal Rural de Pernambuco - Av. D. Manoel de Medeiros, s/n, Dois Irmãos - \\ 52171-030 - Recife - PE
}

Recebido em 8/12/95; aceito em 16/4/97

\begin{abstract}
THE “DISQUISITIONES” OF THE NATURALIST ARRUDA DA CÂMARA (1752-1811) AND THE RELATIONSHIP BETWEEN CHEMISTRY AND PHYSIOLOGY BY THE END OF THE "CENTURY OF LIGHTS". This work is intended to rescue the field of validity of the "Disquisitiones" by the naturalist Arruda da Câmara placing them in the scientific and historical context of the end of the "Century of Light". Thus, a tentative is made here to reconstruct the debate established among the several theories that served as background of the relationships between Chemistry and Physiology of that time. In the present work is presented by the first time an integral translation of the "Disquisitiones" and a biographical resume of the naturalist in the historical context of his epoch in Northeast Brazil, especially in Pernambuco.
\end{abstract}

Keywords: history of chemistry; physiology in the eighteenth-century; Arruda da Câmara.

\section{INTRODUÇÃO}

O presente estudo pretende resgatar o campo de validade das "Disquisitiones" do naturalista Arruda da Câmara, situando-as no contexto histórico-científico do final do Século das Luzes.

Assim, tenta-se reconstruir o debate travado entre as diversas teorias que serviram de pano de fundo das relações entre a Química e a Fisiologia da época.

Objetiva-se superar, desse modo, uma história da ciência de cunho empiricista que, no seu conteúdo, elimina as questões pendentes, as controvérsias, as discussões, as falsas pistas, os campos de validade, os obstáculos epistemológicos e ideológicos. Só apresentam-se as contribuições acumulativas, que parecem definitivas (como tijolos de uma construção) que não serão mais questionadas. Eliminam-se as teorias ditas "falsas": frutos de erros ou divagações.

Apresenta a ciência, enfim, como um produto acabado, esterilizado, insípido, sem história, sem humanidade, praticada por sábios ou gênios solitários e dotados de muita sorte.

Por outro lado, é impossível ignorar o papel de Arruda da Câmara como homem do seu tempo, como cidadão, que parece ter exercido uma ação política marcante na preparação do movimento revolucionário republicano de 1817 , em Pernambuco.

Tenta-se mostrar que esse papel não foi desvinculado da sua notável obra científica. Muito pelo contrário, era parte integrante da sua formação iluminista, que, pressupunha um otimismo no poder da razão em reorganizar o mundo humano e no papel preponderante (das "luzes") da ciência para o progresso dos povos e das nações.

Do ponto de vista da sua organização, o presente trabalho baseia-se, fundamentalmente, nas "Obras Reunidas de Arruda da Câmara" $(1982)^{1}$, coligidas e organizadas pelo historiador pernambucano José Antônio Gonsalves de Mello, autor de valioso estudo biográfico do naturalista. Divide-se assim, em tres partes: na primeira, é apresentada uma tradução integral das "Disquisitiones"; na segunda, a tese do naturalista é discutida no contexto das diversas doutrinas químicas e fisiológicas do final do século XVIII e na terceira, é apresentado um resumo biográfico e análise da ação do naturalista no contexto histórico do Nordeste, principalmente em Pernambuco, de sua época.

\section{INVESTIGAÇÕES FISIOLÓGICO-QUÍMICAS SOBRE A INFLUÊNCIÁ DO OXIGÊNIO NA ECONOMIA ANIMAL, PRINCIPALMENTE NO CALOR E NA COR DOS HOMENS}

Algumas Investigações Fisiológico-Químicas a Respeito da Influência do Oxigênio na Economia Animal, Principalmente no Calor, do qual é a Verdadeira Causa de Equilíbrio

A Química, da qual, em sentido lato, todas as ciências são devedoras ${ }^{1}$, principalmente a Medicina, como se as conduzisse pela mão, ensina-nos, com sólidos argumentos, que a fixação do oxigênio é a causa da quentura e da cor rubra do sangue. Os pulmões são os órgãos onde se realiza a decomposição do ar atmosférico que respiramos, e ali, segundo a afinidade química, separa-se, certamente, em dois: azoto e oxigênio; aquele é exalado pelos pulmões, com alguma proporção de ácido carbônico, voltando à atmosfera; o oxigênio, porém, fica com o sangue. Isto pode-se provar com mil experiências, das quais a principal é a análise do ar respirado, o qual anteriormente composto de oxigênio e azoto, após a respiração contém, apenas, azoto; existem muitas outras provas, como a existência dos ácidos nos corpos vivos, os quais (ácidos) não podem ser formados sem o oxigênio, que é o único princípio acidificante.

$\mathrm{O}$ que faz o oxigênio no corpo dos animais?

Além de muitas utilidades por nós desconhecidas, possui as seguintes:

1) Quando o oxigênio combina-se, o calórico que anteriormente o sustentava no estado gasoso, libera-se, misturando-se

\footnotetext{
Não estou fazendo igual àqueles seguidores que, iludindo outros tolos, para valorizar alguma ciência, eleva-a até as estrelas, mergulhando as outras no abismo com calúnias malignas; para estes, devese lembrar a fábula da raposa que dizia as uvas estarem verdes, simplesmente porque seus dentes ávidos não podiam atingí-las.
} 
na corrente sangüínea, percorre todas as partes, ficando ali para manter o equilíbrio e, por afinidade, este calórico é necessário, principalmente, para manter os líquidos do corpo em seu estado de liquidez; de outro modo, em breve, coagular-se-iam, para conter o grande frio experimentado no inverno, quando o calórico sai do corpo.

2) O oxigênio combinando-se com diversos princípios acidificáveis forma diversos ácidos necessários à economia dos animais. Por exemplo, quando se combina com o fósforo, gera ácido fosfórico, o qual unido com a cal, forma fosfato de cálcio, necessário a composição dos ossos etc; quando combinado com o carbono, compõe o ácido carbônico, o qual unido a uma porção do calórico saída da pele e dos pulmões, é liberada para o éter, na forma gasosa, influenciando a cor dos homens, como veremos, em seguida.

Do que foi dito, deduz-se que, quanto maior o pulmão com relação ao corpo, tanto maior será a quantidade de oxigênio fixado. Isto confirma-se pelas observações dos ilustres Buffon e Broussonet etc, os quais observaram que os animais possuidores de maiores pulmões são os que possuem mais calor.

Por que, então, o calor animal permanece, constantemente, no mesmo grau em qualquer espécie animal, quer viva em atmosfera quente ou fria, quer viva em clima quente ou frio?

Para explicar esse fenômeno não se deve recorrer ao principio vital, nem tão pouco a uma âncora sagrada.

Se um animal viver numa atmosfera igual a seu corpo, sem sentir calor ou frio, o calórico do próprio corpo está em equilíbrio com o calórico da atmosfera. Supondo-se que viva numa atmosfera mais fria, o calórico será transferido do animal para a atmosfera, enquanto o animal sentir frio e, se a perda desse calórico não fosse compensada por outro meio qualquer, em breve, pereceria, destituído de todo o calórico; ao contrário, colocado numa atmosfera muito quente; com maior razão o animal será aquecido, se alguma coisa não o ajudasse a reverter esse mal. A mãe natureza não tardará a apresentar um remédio.

No primeiro caso apresentado, o ar atmosférico condensa-se na proporção do frio, assim, se a atmosfera baixar dois graus, o ar receberá dois graus de condensação, e, então, o animal, num volume igual do ar que respira, deve receber uma maior quantidade de oxigênio, na proporção da condensação, consequentemente, o animal receberá uma quantidade de calórico igual a que perde.

Assim, como o calor natural do homem é de 32 graus, suponhamos que a temperatura desça de uma fração de $3 / 32$, então, dos 32 do animal saem para a atmosfera uma fração de $3 / 32$, para restaurar 29; mas, como o ar condensa-se de uma fração 3/32, o espaço ocupado, anteriormente, no pulmão era de uma polegada cúbica, deve ser ocupado de uma fração 3/32, o calórico superabundante, correspondente a 3/32 polegadas cúbicas de ar, equilibrará o que foi perdido.

Para que vejamos mais claro, um exemplo: uma criança no ventre materno não sente calor nem frio; circundado pelo corpo materno, tem a mesma temperatura, ou seja, cerca de 32 graus; quando vem à luz, se a atmosfera estiver mais fria $3 / 32$ do que sua temperatura, comunica à atmosfera 3/32; mas essa perda será reparada pela respiração contínua que a criança exerce no momento da natividade.

Uma vez que a força digestiva dos pulmões é finita, ocorre que, no frio máximo, o animal não pode fazer a digestão de todo o oxigênio que respira; e, por isso, como não pode reparar a perda do calórico que sai por toda a superfície do corpo, necessariamente morre congelado. Daí a necessidade de indumentária proporcional ao frio. Eis a razão pela qual a natureza proporcionou aos animais de climas frios, como vestimenta, pelos densíssimos; às aves que voam numa atmosfera mais alta e por isso, mais fria, a mesma natureza concedeu plumas densíssimas e, também, pulmões maiores do que os dos outros animais. O homem que é coagido a viver fora de sua pátria, isto é fora dos trópicos, não recebeu da natureza uma indumentária para vencer o rigor do frio; por isso, torna o clima mais quente fabricando vestes, cruelmente retiradas à força de outros animais.

Eis de que modo os animais, em temperaturas ou climas frios, conservam um grau constante de calor natural; do que foi dito, também, pode-se compreender o modo como um grau constante de calor existe nos animais que habitam temperaturas quentes ou clima escaldante; neste caso, como o ar é mais rarefeito, na razão direta do calor, deve fixar uma quantidade menor de oxigênio nos pulmões, e, consequentemente, comunicar menos calórico ao corpo, por essa via; mas, o calórico que é transmitido ao animal pela atmosfera, que talvez fosse suficiente para queimá-lo, de que modo a sábia natureza pode reverter esse mal? Nada é mais fácil do que instruir sobre as ciências físicas e químicas àqueles que as ignoram totalmente; para reverter esta lei, a natureza concedeu uma outra lei geral: toda evaporação deve ser compensada por uma refrigeração $o^{2}$.

E assim, se o clima ou a atmosfera estiver muito quente, há necessidade de refrigeração, sempre na razão da quentura e da superfície; assim a refrigeração deve ser 3, 4, 5, 6 etc, se o calor for 3, 4, 5, 6 etc; daí a necessidade que possuem os animais de beber mais água no verão do que no inverno, para suprir a evaporação. Eis a razão pela qual o grau de calor deve ser sempre o mesmo em qualquer espécie animal, mesmo vivendo em temperatura muito quente.

Daí ser muito fácil entender a causa de muitos fenômenos, que muitos fisiologistas que ignoravam essa lei da evaporação atribuíam injustamente a outras causas. Eis alguns exemplos: porque em temperaturas altas, o termômetro desce ao ser imerso na boca do homem; porque alguns homens sentem frio quando expostos ao sol ou quando tomam banho quente; porque os animais quando queimados, só sentem algum alívio, quando molhados com algum líquido volátil, como, por exemplo, o álcali volátil (amoníaco); porque as mãos refrigeram-se quando molhadas com um líquido de fácil evaporação, por exemplo, o espírito do vinho (álcool), etc.

$\mathrm{O}$ oxigênio também influencia na longevidade da vida do animal, como afirma o meu preceptor D. Dorithes; os animais em que a combustão do oxigênio é menor, têm uma vida mais longa, temos exemplos entre os anfíbios, peixes e outros em que uma vida mais longeva corresponde a uma respiração e transpiração muito menores em relação a outros animais, principalmente os mamíferos.

\section{De Algumas Outras Observações que Permitem Suspeitar que o Oxigênio é a Causa das Diversas Cores dos Homens}

Ninguém duvida que os objetos são coloridos, produzindo ilusões de coloração de algum modo, possuem o poder de decompor certos raios luminosos, absorver e refletir outros; este poder, ou propriedade de decompor as partes, depende, principalmente, de dois fatores como veremos: 1 - Em primeiro, depende da luz enquanto agente que impede o oxigênio de se combinar; pelo seu impacto, diminuindo a atração mútua pelos corpos; 2 - Deve-se ao próprio oxigênio, que ao se combinar com os diversos corpos, faz aparecer cores mais ou menos intensas.

Esta sentença pode ser provada com muitos fatos que podem ser encontrados nos tres reinos da natureza ${ }^{3}$; assim, os óxidos metálicos adquirem cores mais intensas quanto maior for a porção de oxigênio com que se combinem; a fermentação nos vegetais e animais deve-se ao oxigênio; a cor dos frutos maduros deve-se a presença do oxigênio; para ser breve acrescentarei

\footnotetext{
2 Ver Lavoisier

${ }^{3}$ Ver as doutrinas do meu preceptor D.Chaptal, Elementos de Química, t.3, p140, \& D.Dorthes, em sua tese para uma vaga de cátedra régia.
} 
outros fatos, juntos com minhas conjecturas. Os negros nascem alvos; adquirem gradativamente a cor negra pelo contato com o ar, de tal modo que, após sete dias, a cor negra aparece perfeitamente; isto foi observado muitas vezes, e nenhum habitante quer seja da América ou da África ignora esse fato.

D.Littre, no ano de 1702, fazendo a dissecação de um negro, observou que a parte superior do órgão genital, que não estava coberta pelo prepúcio, apresentava a cor negra, igual as demais partes da superfície do corpo, a parte coberta pelo prepúcio era branca. Uma observação feita por mim, muitas vezes, o que é confirmado pelos habitantes do interior do Brasil: existe naquelas regiões uma certa ave de cor negra, cujo nome vulgar é Urubiu (sic) e por Lineu Vultur aura (Systema Naturae, t.I): este animal é branco após sair do ovo e até idade quase adulta, posteriormente, torna-se paulatinamente negro.

Essas observações provam que o contato com o ar é necessário para produzir a cor negra nos negros e no Vultur aura; mas como o oxigênio é o único componente do ar que se combina com os animais, segue-se que o oxigênio influencia as cores dos homens, que seja negra, amarela, olivácea ou ruiva em maior ou menor quantidade, estas dependem da temperatura, ou da intensidade da luz solar, que, mesmo fria facilita a combinação do oxigênio, diminuindo a atração mútua entre as partículas dos corpos.

Eis a razão provável pela qual os homens rústicos expostos a uma ação contínua do sol não possuem a cor alva dos urbanos, tendem mais para a cor negra, quanto mais intensos forem os raios solares a que estiverem expostos; eis, também, a razão pela qual, as partes que não são cobertas por vestimentas apresentam mais cor do que as cobertas. Os alimentos também concorrem para as cores dos homens; uma vez que os alimentos comunicam suas propriedades e virtudes ao corpo, como consta de várias experiências, entre as quais as enumeradas por nosso ilustre Professor D.Fouquet, daí, aqueles que possuem mais ou menos afinidade com o oxigênio, comunicam essa propriedade ao corpo. Existem ainda muitos fenômenos sobre a cor do homem que não puderam ser explicados até agora, ficando a sua explicação para a posteridade.

É fácil entender que a cor natural do homem não seja a branca, como afirmam alguns autores europeus, conduzidos pelo amor a sua pátria, entre os quais enumeram-se Buffon \& Bomar; desde que a pátria natural dos homens está entre os trópicos, como comprovou excelentemente Lineu (Amenitates Academicae, t.6), na dissertação sobre frutos comestiveis, conclui-se que deve existir uma cor natural entre os trópicos, que não é a branca.

\section{ARGUIDORES:}

Digníssimos Professores Regentes

D.Paulus Josephus Barthez, Chanceler da Universidade e Avaliador D.Gaspardus-Joannes René, Decano

D.Antonius Gouan, Pro-Decano

D.Franciscus Broussonet

D.Franciscus Vigarous

D.Henricus-Ludovicus Brun

D.Henricus Fouquet

D.Joannes-Baptista Baume.

\section{2 - AS "DISQUISITIONES" NO CONTEXTO DAS DOUTRINAS QUÍMICAS E FISIOLÓGICAS DO SÉCULO XVIII}

O trabalho de Arruda da Câmara apresentado à Faculdade de Medicina de Montpellier em 1791, com a finalidade de obter o grau de bacharel, pode até possuir pouco mérito do ponto de vista da construção das ciências. No entanto, quando nos colocamos numa perspectiva histórica, traz-nos o testemunho do debate travado entre diversas teorias, que uma historiografia de inspiração empiricista faz questão de eliminar, por considerá-las "erradas", à luz do desenvolvimento posterior das ciências.
Desse modo, o que para um empiricista convicto poderia parecer pura perda de tempo, numa visão construtivista do conhecimento científico, passa a ser uma tarefa muito importante, pois, trata-se de uma tentativa de reconstruir o contexto histórico e social do desenvolvimento das diversas ciências em que as teorias posteriormente rejeitadas eram atualíssimas.

Este é precisamente o caso das "Disquisitiones" (do latim: "Disquisitiones Quaedam Physiologico-Chemicae de Influentia Oxigenii in Oeconomia Animal, Principue in Calore et Colore Hominum") de Arruda da Câmara ${ }^{1}$, que, embora tratando-se de uma simples monografia de graduação, possui uma surpreendente atualidade no contexto científico do final do século XVIII.

Esta atualidade começa pelo próprio título do trabalho: "Investigações Fisiológico-Químicas Sobre a Influência do Oxigênio na Economia Animal, Principalmente no Calor e na Cor dos Homens". O uso do termo economia animal, remete a uma concepção de fundo mecanicista que instalou-se na Biologia a partir da chamada Revolução Científica. Segundo Canguilhem ${ }^{2}$, quem primeiro fez uso do termo, em 1659, foi o médico inglês Walter Charleton (1619-1707), em seu trabalho: "Exercitationes de Oeconomiea Animali", que foi muito aceito na época, tendo como correspondentes: fábrica animal (Hume) e máquina animal (Buffon e Lavoisier).

Para o mesmo autor ${ }^{2}$, o conceito compreendia uma coordenação de atividades diferentes que asseguravam um bem comum, envolvendo uma divisão físiológica do trabalho. O conceito de economia animal estava envolvido numa teoria abrangente de regulação biológica, entendida como funções controladoras de outras funções, que pela manutenção de certas constantes, permitiam ao organismo comportar-se como um todo. A idéia de reguladores está presente no vocabulário de toda a Fisiologia do século XVIII. Todas as teorias de fundo vitalista ou mecanicista, tinham em comum a crença em uma "vix medicatrix naturae" de tradição hipocrática. Daí a idéia da "regulação" que vai até influir no progresso da tecnologia mecânica que tivesse como efeito tornar as máquinas mais "orgânicas", isto é, mais ordenadas internamente.

Foi precisamente Lavoisier, cujas teorias são o principal referencial teórico das "Disquisitiones", que mecanizou as funções fisiológicas quando estabeleceu com Seguin ("Mémoires sur la Respiration et la Transpiration des Animaux", 1790), os principios reguladores da máquina animal: a respiração, que produz o calor animal; a transpiração, que conserva a temperatura no nível que a natureza fixou; a digestão, que restitui ao sangue as perdas devidas à respiração e a transpiração ${ }^{2}$.

A primeira parte das "Disquisitiones" discute a aplicação dos dois primeiros princípios reguladores de Lavoisier. Este, como Buffon, pensava os organismos como máquinas auto-reguláveis, pois, como escrevia: "a natureza em tudo dispôs reguladores"" $\mathrm{e}$ fazendo a ponte de suas idéias para a sociedade, concluía: "a ordem moral tem, como a ordem física, os seus reguladores, de outro modo, há muito teriam deixado de existir as sociedades humanas, ou talvez nunca tivessem existido"2.

Um outro aspecto da atualidade das "Disquisitiones", prende-se ao seu posicionamento no debate sobre as relações entre a Química e a Medicina, ou mais precisamente: entre a Química e a Fisiologia. Arruda da Câmara, já na primeira frase do seu trabalho toma posição, atribuindo à Química o papel proeminente de condutora das outras ciências, principalmente da Medicina, "como se as conduzisse pela mão". Essa posição ousada e surpreendente levanta vários questionamentos, principalmente, quando se leva em conta o cenário e a época em que se concretiza.

A polêmica envolvendo a Química e a Fisiologia desenvolveu-se ao longo de um período que se estende do Renascimento até meados do século XIX, quando os grupos profissionais alcançaram a sua autonomia e, consequentemente, as diversas disciplinas adquirem estatutos próprios.

De acordo com Debus ${ }^{3}$, ao contrário da Faculdade de Medicina 
de Paris, a escola de Montpellier, onde Arruda da Câmara estudou, desde muito cedo incluiu a Química no currículo do curso médico. Desde 1637 que Sebastian Matte atuava como demonstrador em química médica (preparações químicas de produtos farmacêuticos), sendo o seu primeiro professor no século XVII, Arnaldus Fonsorbe.

Os médicos galenistas, que hegemonizavam a escola de Paris, condenavam e resistiam à introdução da Química na Medicina. Esta polêmica atravessou o século XVII, sobretudo com a relevância dos trabalhos dos iatroquímicos: Paracelso, van Helmont, Thomas Willis e Sylvius. O principal expoente da iatroquímica francesa foi Raymond Vieussens (1637-1715), formado em Montpellier em 1670, que estabeleceu uma polêmica, muito ilustrativa da época, com Philippe Hecquet (16611735) iatrofísico, que atacava a sua concepção química do processo digestivo nos animais ${ }^{3}$.

$\mathrm{O}$ debate entre iatroquímicos e iatrofísicos marcou grande parte da Fisiologia no início do século XVIII, como pode ser constatado nos trabalhos publicados no "Journal des Sçavans"3.

Por outro lado, no sentido da superação da iatroquímica, duas posições na Fisiologia do século XVIII, são paradigmáticas; uma representada por Boerhaave (1668-1738), professor de Medicina e Botânica em Leyden, que por sua formação mecanicista atacava Paracelso e van Helmont por submeterem a Medicina (leia-se Fisiologia) à especulação da Química; outra, representada por Georg Ernst Stahl (1660-1734), médico e professor de Química em Iena e Halle, que, segundo Partington $^{4}$, junto com Becher formulou a falsa teoria do flogisto, rejeitava as teorias iatroquímicas, insistindo na linha de demarcação entre os seres vivos e não-vivos. Para ele a "anima" presidiria os processos fisiológicos que ocorrem nos organismos. Afirmava que os iatroquímicos interpretavam incorretamente os processos vitais e atribuía à Química na Medicina apenas um papel de valor farmacêutico. Era, precisamente, além de um dos formuladores da teoria do flogisto, o principal teórico da doutrina do animismo em Fisiologia: a alma é a reguladora de todos os fenômenos fisiológicos, normais ou patológicos, que ocorrem nos organismos (Théodorides ${ }^{5}$ ).

A fisiologia animista de Stahl difere grandemente da fisiologia mecanicista de Boerhaave, mas ambos circunscreviam a Química a um valor farmacêutico e separavam claramente a especulação dos iatroquímicos da teoria fisiológica. Ambos insistiram em eliminar o papel da Química como meio explicativo dos fenômenos vitais.

Em trabalho mais antigo, Canguilhem ${ }^{6}$, defende a posição de Stahl e afirma que a concepção vitalista, tão difamada pela historiografia empiricista, não entravara a experimentação, nem a conceitualização em matéria de fisiologia. Muito pelo contrário, queria ser um estilo newtoniano de enfoque à originalidade das funções biológicas, eliminando as especulações sobre as suas causas.

Ora, Lavoisier, Laplace e Seguin propuseram substituir a idéia da respiração, interpretada em termos vitalistas, por uma perspectiva determinista, interpretável mediante noções físicoquímicas (Giordán et al. ${ }^{7}$ ). Também as suas descobertas, punham termo (provisório) ao longo debate acerca da origem do calor animal, principalmente com os experimentos sobre o calórico, de Lavoisier e Laplace a partir de 1780.

Segundo Partington ${ }^{4}$, Lavoisier não acreditava que o calor tivesse peso, concebia-o como elemento imponderável ao qual denominou de "calórico" em 1787. Relacionando o calor animal com a respiração, Lavoisier concluiu: "A respiração é, portanto, uma combustão muito lenta, na realidade, muito semelhante a do carvão; faz-se no interior dos pulmões, sem libertar luz sensível, porque a matéria de fogo liberta, é imediatamente absorvida pela umidade destes órgãos; o calor que se desenvolve nesta combustão comunica-se ao sangue que

4 Ver Historie de la Academie des Sciences, 1702, pág. 32. atravessa os pulmões e espalha-se a partir de lá a todo o sistema animal (Théodorides ${ }^{5}$ ).

Quando o autor das "Disquisitiones" passa a explicação da fisiologia da respiração, fundamenta-a em teorias químicas. Embora não cite as suas fontes, utiliza-se da teoria oxigênica, creditada a Lavoisier, como pode ser facilmente verificado, consultando-se o "Traité Élémentaire de Chimie".

Em primeiro lugar, tem-se a descrição e análise do ar atmosférico interpretada de acordo com a teoria oxigênica que, numa visão empiricista, suplantou a teoria do flogisto. Nesse particular, a linguagem do texto permanece compreensível para um leitor hodierno, a não ser no que se refere à nomenclatura do nitrogênio, denominado na literatura química francesa durante muito tempo por azoto. O que, no entanto, desperta mais atenção quando se trata de reconstruir o contexto das idéias vigentes na época em que Arruda da Câmara estudou em Montpellier são duas teorias eliminadas na historiografia da Química: a doutrina do calórico e a função do oxigênio na formação dos ácidos, amplamente referenciadas nas "Disquisitiones".

No caso da Química, essas teorias, defendidas por Lavoisier, foram cuidadosamente eliminadas, em função do engrandecimento daquele que é considerado como um dos fundadores da Química moderna. Segundo essa visão, atribuir-lhe doutrinas "erradas" comprometeria não somente a imagem do cientista, mas, principalmente, o prestígio da Química como ciência.

O calórico desempenha um papel fundamental no sistema teórico construído por Lavoisier. A seção I do "Traité Élémentaire de Chimie" 8 , considerada pelos historiadores, o núcleo teórico do novo sistema construído em torno do oxigênio, inicia-se com capítulo intitulado: "Das combinações do calórico e da formação dos fluidos aeriformes ou gases" 8 . Lavoisier procura construir uma teoria explicativa sobre o que denominamos hoje de estados físicos da matéria em função "de dois poderes opostos; um repulsivo e outro atrativo" 8 . A repulsão teria como causa o calórico. "É difícil compreender esses fenômenos sem admitir que são feitos de uma substância real e material ou de um fluido muito sutil que se insinua entre as partículas dos corpos, separando-as umas das outras" ${ }^{\text {. }}$. Mesmo expressando algumas dúvidas sobre a natureza "fluido", o inclui entre as substâncias mais simples. "E, ainda que se suponha a existência desse fluido como hipotética, veremos, em seguida, que ele explica os fenômenos da natureza de maneira muito satisfatória"8.

Numa obra, extraordinariamente rica em detalhes, fundamentada principalmente nas anotações de laboratório de Lavoisier, Holmes ${ }^{9}$ afirma que, a partir das investigações sobre os processos que fixam ou liberam "ares"(gases), o cientista francês desenvolveu o núcleo central de um novo sistema químico, tanto do ponto de vista conceitual quanto experimental. Nesse programa de pesquisa o processo fisiológico da respiração era um componente integral. Ainda segundo Holmes ${ }^{9}$, o principal objetivo das investigações de Lavoisier sobre a respiração era comparar o calor produzido na respiração com o produzido na combustão do carvão.

Para atingir essa meta, Lavoisier e Laplace, segundo Roberts ${ }^{10}$, idealizaram e mandaram construir um instrumento tradicionalmente conhecido pela denominação de calorímetro de gelo. Na "Mémoire sur la chaleur"de 1783, o aparelho é designado simplesmente de "machine". Seis anos depois, Lavoisier dedica-lhe um capítulo especial no "Traité", sob o título de : "Dos aparelhos relativos à medição do calórico". O instrumento anteriormente denominado de "máquina", passa a ser calorímetro, ou seja, um aparelho para medir o calórico. Rebatizando esse instrumento, Lavoisier o integrava ao novo sistema da química baseada no oxigênio.

Segundo Bensaude-Vincent ${ }^{11}$, o calórico, sendo imponderável, desafia o império da balança. Mas o calorímetro permite contornar esse obstáculo. Na medida em que mede a quantidade de calórico despreendida nas reações químicas, funciona como 
um "analogon" da balança. Além disso, reforça a credibilidade da concepção lavoisiana de gás e, sobretudo, dá as suas teorias e as suas práticas a coerência de um sistema.

Nesse novo sistema, é que se deve entender o significado da palavra gás, empregada inicialmente por van Helmont, e totalmente modificada por Lavoisier: "Gás na nossa nomenclatura torna-se um termo genérico, expressando o grau mais completo de saturação do calórico de um corpo, um modo de existência"8. Gás, portanto, é toda substância simples ou composta em que o grau de saturação do calórico atingiu o máximo.

Somente nesse contexto, pode-se compreender o raciocínio contido nas "Disquisitiones" sobre o papel do oxigênio na respiração: "quando o oxigênio se combina, o calórico é liberado...".

A outra teoria lavoisiana presente no trabalho de Arruda da Câmara, diz respeito à formação dos ácidos. Segundo essa concepção, o oxigênio constitui-se na condição "sine qua non" para a existência de tais substâncias. Aliás, o nome atribuído por Lavoisier ao oxigênio elimina qualquer dúvida que se possa ter a respeito: "Demos...a porção respirável do ar o nome de oxigênio, de "oxos" (ácido) e "geinomai" (engendro, gero) porque, na realidade, uma das suas propriedades mais gerais é gerar ácidos, combinando-se com diferentes substâncias"8.

Crosland $^{12}$, num trabalho sobre a teoria dos ácidos segundo Lavoisier, afirma que a sua teoria oxigênica foi, desde o início, muito mais uma teoria da acidez do que uma teoria da combustão. Segundo este autor, uma das razões do esquecimento da teoria oxigênica da acidez é que ela pode ser considerada como um embaraço. Os historiadores, tradicionalmente, consideram essa teoria uma infelicidade, inclusive, a etimologia do termo oxigênio, desconcerta aqueles que tentam julgar as idéias do século XVIII com os padrões da ciência atual. O autor ${ }^{12}$ não concorda com Partington e com todos aqueles que consideram a teoria oxigênica da acidez como o maior erro de Lavoisier e vai mais longe, defendendo a tese de que não se trata de "erro", e mesmo se fosse, da maneira como foi expressa, propiciou à geração seguinte o ponto de partida para uma teoria melhor.

Depreende-se da leitura de Bensaude-Vincent e Stengers ${ }^{13}$, que o embaraço citado por Crosland ${ }^{12}$ tem uma explicação mais profunda, refletindo uma preocupação dos químicos de apresentar a sua ciência totalmente liberta de qualquer conotação metafísica, de mostrá-la na via triunfal do progresso; ou seja, de apresentar uma história "séria", centrada sobre leis e descobertas experimentais, cujo acúmulo geraria uma multidão de aplicações industriais ou agrícolas, cada vez mais benéficas ao progresso da humanidade.

A segunda parte das "Disquisitiones" se constitui de uma tentativa de explicação da diversidade da cor dos homens, tendo como causa a ação do oxigênio. Também fundamentada na teoria oxigênica, ressaltando a enorme capacidade do oxigênio em combinar-se com outras substâncias.

Segundo $\mathrm{Mello}^{14}$, este tema refleteria o interesse do naturalista por uma indagação que seria comum aos brasileiros: a diversidade de cor da pele da sua população. Não deixam de ser curiosas as suas observações e exemplos, sobretudo o do "Urubiú" e do órgão genital do negro dissecado por Littre.

A tese também não deixa de ser um desafio ao racismo "científico" nascente da época, por enquanto, ainda em sua fase naturalístico-classificatória. Segundo Poliakov ${ }^{15}$, a cor da pele foi o primeiro critério classificatório das "raças" humanas, usado primeiramente por Buffon, com enorme prestígio acadêmico na França. Este, sugeriu o seguinte experimento para estudar-se a modificação da cor dos homens: seria necessário transportar alguns negros do Senegal para a Dinamarca, enclausurá-los e mantê-los com as suas famílias, sem permitir que cruzassem com outras raças. Sendo este o único meio para saber-se quanto tempo seria necessário para reintegrar os negros à natureza humana, e pela mesma razão, quanto tempo foi preciso para mudá-los de brancos para negros ${ }^{15}$. Contrariando
Buffon, Arruda da Câmara sustentatava, apoiando-se em Lineu, que a cor original do homem não poderia ser a branca, já que o seu berço de origem deveria ter sido nos trópicos.

Sacarrão ${ }^{16}$ chama a atenção que Buffon não teve a mesma idéia de "controle de experimento" de enviar alguns dinamarqueses para o Senegal e submetê-los a uma experiência análoga. O mesmo autor ${ }^{16}$ afirma que o grande naturalista Buffon pensava a cor escura dos homens, como um fenômeno de degenerescência devido a ação do clima. Arruda da Câmara usou a análise deste mesmo fator, acrescido da ação do oxigênio, para chegar a conclusão oposta.

Na época em que Arruda da Câmara estudou em Montpellier, a sua Faculdade de Medicina já era um dos mais importantes centros acadêmicos, onde se defendiam as doutrinas de Stahl. Aí pontificavam os seus discípulos mais importantes: Théophile Bordeu (1722-1776) que, em fisiologia, localizava as forças vitais em cada órgão e, principalmente, Paul-Joseph Barthez (1734-1806) que sustentava um único princípio vital para todos os fenômenos fisiológicos do organismo. Na sua opinião, a Química seria uma boa explicação para a natureza morta, jamais para os fenômenos vitais. Segundo Debus ${ }^{3}$, a sua obra de 1778: "Noveaux Élements de la Science de l'Homme", se constitui em um libelo contra as explicações químicas dos fenômenos fisiológicos.

Foram Bordeu e Barthez os principais responsáveis pelo estabelecimento em Montpellier da longa tradição de divórcio entre a Química e as teorias de fisiologia médica, restringido o papel desta ciência a preparação de produtos farmacêuticos. Esta tradição, mais tarde assumida por Xavier Bichat (17711802), o mais proeminente representante da escola médica de Montpellier, que insistiu com vigor na separação da Física e da Química das explicações dos fenômenos físiológicos. Assim, em Montpellier, estabeleceu-se uma fisiologia médica vitalista e não-química durante o final do século XVIII e todo o século XIX ${ }^{3}$.

É neste contexto que a tese de Arruda da Câmara apresenta-se como uma verdadeira provocação. Aliás, a nota de rodapé que acompanha a primeira frase do seu trabalho, constitui-se, aparentemente, numa "boutade" contra os defensores de Stahl, entre os quais, o mais proeminente era, sem dúvida, Barthez, justamente o chanceler universitário e presidente da banca examinadora do seu trabalho! A invocação da fábula da raposa e das uvas naquele meio acadêmico soava como uma verdadeira bofetada.

O que teria acontecido? Uma tentativa de desmoralização dos seguidores de Stahl? Efeitos na Academia da Revolução em curso? Afinal, Luís XVI e família acabavam de ser presos em Varennes e arrastados de volta à Paris. Defender a Química como fonte de explicação dos fenômenos fisiológicos, no final do século XVIII em Montpellier, na presença de Barthez, soava como uma heresia.

Teria sido a tese de Arruda da Câmara realmente aprovada? Pelo contexto analisado teriamos concluído que não, que seria absurda tal aprovação. Mas o seu principal biógrafo, Prof. José Antonio Gonsalves de Mello ${ }^{14}$, notável estudioso da nossa história regional, assinala: "A conclusão pareceu aceitável à banca examinadora da tese...e a Arruda foi deferido o grau acadêmico" 14

\section{3 - O NATURALISTA ARRUDA DA CÂMARA NO CONTEXTO HISTÓRICO DO NORDESTE, ENTRE O FIM DO SÉC.XVIII E O INÍCIO DO SÉC.XIX}

É difícil acreditar-se que, sobre um dos mais importantes naturalistas brasileiros, não haja comprovação histórica de datas e locais do seu nascimento e morte. Mas isso é o que acontece com Arruda da Câmara. Escreve o seu principal biógrafo $^{14}$, que foram seus pais: Francisco de Arruda Câmara, capitão-mor das Ordenanças de Piancó, grande senhor de terras e 
rebanhos de gado e $\mathrm{D}^{\mathrm{a}}$. Maria Saraiva da Silva, naturais do sertão paraibano.

De acordo com o historiador Maurílio Augusto de Almei$\mathrm{da}^{17}$, o referido casal teve prole numerosa, destacando-se: Manoel de Arruda Câmara, o médico e naturalista; Francisco de Arruda Câmara, médico e deputado às Cortes de Lisboa e Ana de Arruda Câmara, que foi casada com Antônio Ferreira de Macêdo, que por sua vez, foram pais de Estevão José da Rocha, o Barão de Araruna, titular do Império, com numerosa descendência na Paraíba.

Frei Lino do Monte Carmelo, cronista da Ordem Carmelita, citado por Mello ${ }^{14}$, registra que Arruda da Câmara havia nascido em Pombal (PB) em 1752 e professara na Ordem Carmelita, no Convento de Goiana, em 1783, adotando o nome religioso de Frei Manoel do Coração de Jesus. Teria então, 31 anos de idade, demonstrando uma vocação tardia para a vida religiosa.

Tres anos depois (1786), deixou a vida monástica e partiu, com o pai e o irmão Francisco, para a Europa. Em outubro do mesmo ano, matriculou-se no Curso de Filosofia em Coimbra, assinando-se, no ato da inscrição, como: "Frei Manoel do Coração de Jesus Arruda, religioso carmelita calçado, natural do Certam de Paranambuco"14. Declaração de naturalidade que insistiu durante toda a sua vida, sem explicação: tudo indica que era paraibano e ele próprio considerava-se pernambucano.

Quatro anos depois, o irriquieto frade, abandonou seus estudos em Coimbra e passou à França revolucionária, onde a 15 de agosto de 1790, matriculou-se na Faculdade de Medicina de Montpellier, assinando-se "Manoel Arruda" ou "Emmanoel Arruda", como consta da sua tese.

O que teria motivado decisão tão importante na sua vida? Segundo o historiador Pereira da $\operatorname{Costa}^{18}$, teria deixado Coimbra por causa das perseguições das autoridades portuguesas aos estudantes simpáticos ao ideário da Revolução Francesa. Mas, de acordo com Mello ${ }^{14}$, suas convicções políticas estavam mais próximas de uma monarquia ilustrada do que de uma república democrática.

De resto, demonstrava uma marcante influência filosófica de Condillac e científica de Lavoisier. Outras influências da sua concepção científica, foram: Brotero e Gouan na Botânica e Chaptal em Química, que mais tarde foram homenageados em nomes específicos de vegetais brasileiros que descreveu.

Após a curta duração dos seus estudos médicos, a 2 de setembro de 1791, graduou-se em medicina pela Universidade de Montpellier ${ }^{14}$, já maduro então, aos 39 anos de idade, com defesa da tese objeto de estudo do presente trabalho.

No ano seguinte, passou novamente a Portugal, sem impedimento das autoridades, e publicou o "Aviso aos Lavradores Sobre a Inutilidade da Suposta Fermentação de Qualquer Qualidade de Grão ou Pevides, Para Aumento da Colheita, Segundo um Anúncio Que Se Fez ao Público", editado em Lisboa, $1792^{14}$.

Já em 1793, regressou ao Brasil, e no ano seguinte, empreendeu uma vasta expedição científica pelo Nordeste, que durou até setembro de $1795^{14}$.

Após essa viagem, instalou-se em Pirauá (PB), onde estabeleceu, às margens do Paraíba, uma grande fazenda, na qual cultivou intensamente o algodão. Enquanto isso, o seu irmão Francisco, instalou-se em Goiana, onde praticou a medicina e tornou-se o senhor do Engenho Goiana Grande, em terras onde hoje existe a Usina N. S. das Maravilhas.

Nesse período, Arruda da Câmara, intensificou os seus estudos de Botânica aplicada, trocando idéias através de correspondência com o famoso botânico mineiro Frei José Mariano da Conceição Veloso (1741-1811), autor da "Flora Fluminense".

Como resultado da sua experiência de cutinicultor, em 1797, publica a notável "Memória Sobre a Cultura dos Algodoeiros", que constitui-se num verdadeiro tratado sobre essa cultura.

Por outro lado, também assumiu o cargo oficial de "Naturalista de Sua Majestade Fidelíssima", encarregado de procurar salitreiras e minas em Pernambuco, S. Francisco e Jacobina na Bahia.
Sua área de estudos e coletas abrangeu os atuais Estados de Pernambuco, Paraíba, R. G. do Norte, Ceará, Maranhão, Alagoas, Sergipe e Bahia, quase o Nordeste inteiro, portanto. Sua prioridade de interesse era, em primeiro lugar, em relação aos vegetais; em seguida, aos animais, notadamente os insetos e, finalmente, aos minerais, por obrigação do ofício ${ }^{14}$.

A partir do início do século XIX, fixou-se em Goiana, onde gozou de grande reputação e cuidou de negócios particulares, principalmente, do fornecimento de carnes. Por outro lado, estabeleceu uma longa e duradoura amizade com o Pe.João Ribeiro Pessoa de Mello Montenegro, ao qual referia-se por "meu amigo e discípulo", que foi o principal ilustrador das estampas dos seus trabalhos científicos e, mais tarde, um dos principais dirigentes do movimento revolucionário republicano de 1817 , em Pernambuco ${ }^{14}$.

Em 1810 publicou a "Dissertação Sobre as Plantas do Brasil Que Podem Dar Linhos Próprios Para Muitos Usos da Sociedade, e Suprir a Falta do Cânhamo" e o "Discurso Sobre a Utilidade da Instituição de Jardins nas Principais Províncias do Brasil", onde defendeu a introdução de plantas exóticas úteis no Brasil e, pioneiramente, alertou para a ameaça de extinção de espécies vegetais nativas, como o cruatá e a carnaubeira ${ }^{14}$.

Aos 59 anos de idade, solteiro e sem descendentes, faleceu em data e local ignorados. Koster, citado por Mello ${ }^{14}$, afirma que o naturalista morreu em Goiana em 1811, vitimado por uma "hidropsia do peito". Outros dizem que morreu no Recife.

Fato estranho que Arruda da Câmara, parece nunca ter exercido a medicina, com as idéias que tinha sobre a aplicação dos conhecimentos, certamente influenciado pelas orientações da Academia Real das Ciências de Lisboa, da qual fazia parte desde 15 de maio de $1793^{14}$, que desde a Reforma Pombalina, visava a prática científica com fins mais utilitários que os meramente descritivos e classificatórios, principalmente nas colônias ultramarinas ${ }^{16}$, pois vivendo numa região tão carente de médicos até nos nossos dias, imagine-se em seu tempo.

A maior parte do seu espólio científico inédito desapareceu na voragem da repressão monarquista ao movimento republicano de 1817. Do conjunto, eram os mais notáveis:

1 - As centúrias dos novos Gêneros e Espécies das Plantas de Pernambuco (Flora Pernambucana);

2 -Uma tradução do "Traité Élémentaire de Chimie" de Lavoisier, que datava da época dos seus estudos na França e que teria sido orientada pelo próprio Lavoisier;

3 - Uma tradução da "Lógica" de Condillac;

4 - Um "Tratado Sobre Destilação", com modelo de alambique aperfeiçoado;

5 - Uma "Nova Insetologia", segundo o sistema de Lineu e com novas descrições de Espécies de insetos do Nordeste;

6 - Um "Compêndio de Agricultura Brasiliense", de conteúdo prático, com desenhos e descrições de máquinas agrícolas inventadas ou aperfeiçoadas;

7 - Vários relatórios de expedições científicas ${ }^{14}$.

Quanto à sua ação política, Arruda da Câmara foi apontado pela repressão monarquista ao movimento revolucionário de 1817, como um dos principais responsáveis pela doutrinação e divulgação de idéais revolucionárias e introdutor da Maçonaria em Pernambuco ${ }^{14}$.

O historiador Teobaldo Machado ${ }^{19}$, citando os autos da devassa ao movimento de 1817, nas declarações de um dos devassantes, que afirmava: "As idéias comunicadas pelos dois Arrudas, médicos de Goiana, cresceram e propagaram pelo estabelecimento de Lojas Maçônicas". A origem dessas, teria sido o célebre Aerópago de Itambé, que, segundo o historiador Horácio de Almeida ${ }^{20}$ : "fundado pelo naturalista paraibano Arruda da Câmara, em 1799”. Tendo escolhido Itambé por ser uma localidade estratégica, na fronteira das duas províncias. Alí, teria disseminado as idéias da Revolução Francesa contra 
o absolutismo monárquico português; preparado adeptos para um sistema republicano, essencialmente democrático, com noção da dignidade do homem, sem diferenciação entre homens brancos, pretos ou pardos ${ }^{20}$.

O historiador paraibano Maximiano Lopes Machado ${ }^{21}$, escreveu que "o ilustre sábio, natural do sertão da Parayba", apenas recém chegado da Europa, partiu para Pedras de Fogo e fundou o Aerópago de Itambé, onde doutrinava o povo para a emancipação da pátria contra o despotismo ${ }^{16}$. Quanto ao seu irmão Francisco, ainda vivo e atuante quando do movimento de 1817 , dele participou diretamente, de bacamarte em punho, nas escaramuças contra os monarquistas nas ruas de Goiana, como informaram testemunhas da devassa ${ }^{19}$.

Nessa historiografia, Mello ${ }^{14}$, posiciona-se como uma das vozes discordantes das versões da participação do naturalista na preparação do movimento de 1817, questionando a falta de documentação histórica e as biografias, que diz "impõe-se desbastar". Um dos aspectos em que é mais contundente, sobre o decantado humanismo do naturalista (e também senhor de escravos) para com os negros. Nesse caso, cita passagem da "Memória Sobre a Cultura dos Algodoeiros", onde o naturalista afirmava a "natural preguiça"dos negros, tendo os seus "roubos, enganos e falsidades" de ser castigados sem hesitação, com "palmatoadas", pelos feitores encarregados da sua vigilância. Essas opiniões escritas, naturalmente, estão em flagrante contradição com as idéias contidas na sua suposta "carta-testamento", dirigida ao Pe. João Ribeiro. Outras idéias contidas nessa carta, constituem uma declaração de fé na independência do Brasil, tendo consciência de que não a alcançaria, quando afirmava: "Sou dos agricultores que não colherei os frutos do meu trabalho, mas a semente está plantada com boas batatas" 18 .

A posição de $\mathrm{Mello}^{14}$, entretanto, é isolada em relação a maioria dos historiadores regionais que sustentam uma ampla participação de Arruda da Câmara como principal ideólogo do movimento revolucionário republicano de 1817.

Dentre as suas múltiplas faces, a do ilustrado naturalista, a do fazendeiro senhor de escravos, a do fornecedor de carnes verdes de Goiana e a do "sans culotte" matuto, emerge o homem desnudo, sem a mitologia do herói da história oficial, sem o alheamento estereotipado do cientista. Emerge o homem do seu tempo, representante típico do iluminismo entre nós, com a aguda consciência da aplicação prática dos seus conhecimentos científicos em benefício da sua pátria. Daí, as suas críticas à erudição confinada em gabinetes de estudo. Daí, porque só concebia os seus conhecimentos botânicos aplicados à agricultura, à industria e à medicina, como testemunham todas as suas obras.

\section{REFERENCIAS}

1. Arruda da Câmara, M.; Manuel Arruda da Câmara - obras reunidas ; Fundação de Cultura Cidade do Recife; Recife, $1982 ;$ p.75-84.

2. Canguilhem, G.; Ideologia e racionalidade nas ciências da vida ; Edições 70; Lisboa, 1977; p.78, 79, 80, 81, 82.

3. Debus, A. G.; Quím. Nova 1992, 15, 262.

4. Partigton, J. R.; Historia de la Quimica; Espasa-Calpe Argentina; Buenos Aires, 1945; p.99, 145.

5. Théodoridés, J.; História da Biologia; Edições 70; Lisboa, 1984; p.53, 54, 55.

6. Canguilhem, G.; A fisiologia animal; In: Taton, R.(org.); História geral das ciências; Dife; São Paulo, 1959; p.180, 181.

7. Giordán, G.; Raichvarg, D.; Drouin, J. M. et al; Conceptos de Biologia 1; la respiración; los microbios; el ecosistema; la neurona; Editorial Labor; Madrid, 1985; p.52.

8. Lavoisier, A. L.; Traité élémentaire de chimie; GauthierVillars Editeur; Paris, 1937; p.1, 30, 31, 32, 152.

9. Holmes, F. L.; Lavoisier and the chemistry of life, an exploration of scientific creativity; The University of Winsconsin Press; Winsconsin, 1985; p.1, 189.

10. Roberts, L.; Isis 1991, 82, 198-222.

11. Bensaude-Vincent, B.; Lavoisier: Mémoires d'une révolution ; Flamarion; Paris, 1993; p.218, 219, 299, 300, 304, 376,410 .

12. Crosland, M.; Isis 1973, 64, 306.

13. Bensaude-Vincent, B.; Stengers, I.; Historie de la Chimie; Éditions La Decouverte; Paris, 1995; p.6.

14. Mello, J. A. G.; Estudo biográfico ; In: Arruda da Câmara, M.; Manuel Arruda da Câmara - obras reunidas; Fundação de Cultura Cidade do Recife; Recife, 1982; p.11-74.

15. Poliakov, L.; O mito ariano: ensaio sobre as fontes do racismo e dos nacionalismos; EDUSP; São Paulo, 1974; p.142, 143, 144 .

16. Sacarrão, G. F.; Biologia e sociedade - II: o homem indeterminado; Europa-América; Lisboa, 1989; p.119, 120.

17. Almeida, M.; O barão de Araruna e sua prole ; Ed. do autor; João Pessoa, 1978; p.15.

18. Costa, F. A. P.; Dicionário biográfico de pernambucanos célebres; Fundação de Cultura Cidade do Recife; Recife, 1982; p. 640-644.

19 Machado, T.; As insurreições liberais em Goiana; Fundarpe; Recife, 1990; p.47.

20 Almeida, H.; História da Paraíba; Ed. UniversitáriaUFPB; João Pessoa, 1978; p.90.

21 Machado, M. L.; História da província da Paraíba ; Ed. Universitária-UFPB; João Pessoa, 1977; p.127. 